\title{
Study on Electro Hydraulic Force Servo System Considering Spool Friction and Cylinder Piston Friction Nonlinear
}

\author{
Jianying LI* \\ School of Mechanical and Power Engineering, \\ Harbin University of Science and Technology, \\ Harbin China, \\ E-mail: ljyhit@163.com \\ +* Corresponding author \\ Yanwei WANG \\ School of Finance, \\ Harbin University of Commerce, \\ Harbin China, \\ E-mail:wywnancy@163.com

\section{Shiming LI} \\ School of Mechanical and Power Engineering, \\ Harbin University of Science and Technology, \\ Harbin China \\ E-mail: 13313697332@qq.com
}

\author{
Zhongqiang ZHAO \\ School of Mechanical and Power Engineering, \\ Harbin University of Science and Technology, \\ Harbin China, \\ E-mail: 425297774@qq.com
}

\author{
Guihua HAN \\ School of Mechanical and Power Engineering, \\ Harbin University of Science and Technology, \\ Harbin China, \\ E-mail: 641544105@qq.com
}

\section{Fatang DONG}

School of Mechanical and Power Engineering, Harbin University of Science and Technology, Harbin China E-mail: 1805382297@qq.cm

\begin{abstract}
In order to give full play to the performance of electro hydraulic force servo system in engineering applications, especially its good dynamic performance, the electro hydraulic force servo system and its bond graph model built process are analyzed. In this course, aiming at the time varying nonlinear characteristics of the hydraulic cylinder cavity with the displacement of the piston rod, the nonlinear characteristics of friction in the system such as spool friction and cylinder piston friction, valve orifice flow nonlinearity etc. these actual existence difficult building model characteristic in theoretical research and practical application, we play the advantage of bond graph theory that can contain multiple nonlinearities, that is applied to the simulation of nonlinear systems, and that can be used to establish the system model based on the direction of power flow in the system. Then the bond graph model of electro hydraulic force servo system is established, and the correctness of the new model is verified by simulation research, this study also has a good reference for other related research.
\end{abstract}

Keywords-electro hydraulic force servo system; time variant nonlinear cavity; spool friction; cylinder piston friction; valve orifice flow nonlinearity; bond graph model

\section{INTRODUCTION}

Electro hydraulic force servo system has many advantages, such as large power to volume ratio, fast response, strong load disturbance resistance and so on ${ }^{[1]}$, It has been widely used in the field of metallurgy rolling mill, heavy equipment, aircraft or large ship control system, large scale scientific experimental device and so on $^{[2]}$. In theoretical research and practical application, parameter time varying characteristics of electric hydraulic force servo system, nonlinear friction characteristics such as spool friction and cylinder piston friction, and valve orifice flow nonlinearity and so on these factors are really existing, these factors make the electro hydraulic force servo system performance in the application, especially the dynamic performance is greatly limited ${ }^{[3]}$.

The bond graph theory is used to unify various physical parameters into four state variables, at the same time, it is used to represent the basic physical properties and describe the basic connection mode of power conversion and conservation, it can make the bond graph model of the system according to the direction of power flow in the system ${ }^{[4]}$; the model corresponds to the physical model of the system, and it has a unique superiority ${ }^{[5]}$. At the same time, the process of deriving the state equation from the bond graph is very regular, and it can also contain many kinds of nonlinearity, so it is suitable for simulating nonlinear systems ${ }^{[6]}$. In this paper, the bond graph theory is used to establish the nonlinear model considering the nonlinear factors, such as spool friction and cylinder piston friction nonlinear, and verify its correctness, but also provide a useful basis for other similar research. 


\section{BOND GRAPH MODEL OF ELECTRO HYDRAULIC SERVO VALVE}

The dynamic characteristic of the electro hydraulic servo valve refers to the physical response process through electric suction process and power release process of coil current, spool displacement, electromagnetic force and motion of the dynamic resistance ${ }^{[7]}$. The response process has undergone an electric-magnetic-force-motion process; the coupling relationship is shown in Fig. 1, the working process can be described by electrical equation model, magnetic equation model and mechanical motion equation model.

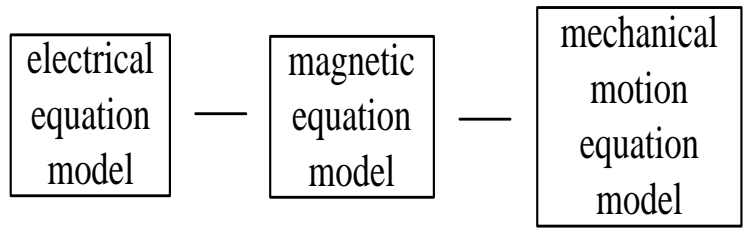

Figure 1. Coupling relationship between the components of electro hydraulic servo valve

\section{EleCtrical Equation Model of Electro HYDRAULIC SERVO VALVE}

When considering only the electro hydraulic servo valve coil resistance and coil inductance ${ }^{[8]}$, then:

$$
u=i R+\frac{d(N \Phi)}{d t}=i R+N \frac{d(\Phi)}{d t}
$$

Where: $u$ - Coil excitation voltage (V), $i$ - Coil current (A), $R$ - Coil resistance ( $\Omega$ ), $N$ - Coil number, $\Phi$ Magnetic flux (Wb).

\section{Magnetic Equation Model of Electro Hydraulic SERVo VALVE}

According to the basic theorem of Kirchhoff's magnetic circuit, we can get the magnetic equation model ${ }^{[9]}$,namely:

$$
N i=\Phi R_{m}=\Phi \frac{l_{0}+x}{\mu_{0} S}
$$

Where: $R_{m}$ - Total reluctance of electromagnet $(\Omega), l_{0}$ Initial air gap length (m), $x$ - Spool displacement (m), $\mu_{0}$ Air permeability $(\mathrm{H} / \mathrm{m}), S$ - Pole area $\left(\mathrm{m}^{2}\right)$.

\section{Mechanical Motion Equation Model of Electro Hydraulic SERVo Valve}

When the solenoid is energized after the coil is electrified to generate electromagnetic force, to overcome the spring preload and friction force attracts the armature push rod, the spool moves, the dynamic equation of the model can beexpressed as ${ }^{[10]}$ :

$$
\begin{gathered}
F-\left(2 k+K_{x} \Delta p\right) x-\left(C_{v}+C_{f}\right) \frac{d x}{d t}+K_{x} \Delta p d_{0}=m \frac{d^{2} x}{d t^{2}} \\
F=\Phi^{2} / 2 \mu_{0} S
\end{gathered}
$$

Where: $F$ - Magnetic Adhesion(N), $k$ - The spring stiffness coefficient of the electro hydraulic servo valve(N/m), $K_{x} \Delta p$ - Steady state hydrodynamic force dynamic stiffness coefficient, $K_{x}$ - Steady hydrodynamic coefficient, $\Delta p$ - Pressure difference before and after valve orifice $\left(\mathrm{P}_{\mathrm{a}}\right), C_{v}$ - Velocity damping coefficient of electro hydraulic servo valve(Ns/m), $C_{f}$ - Viscous damping coefficient of oil(Ns/m), It is said that the movement of the spool due to the viscosity of oil produced by friction, $d_{0}$ Valve cover length(m).

Electro hydraulic servo valve is mainly based on throttling characteristics to work, in the establishment of the bond graph model, the need to consider the servo valve dead zone and saturation characteristics, the friction characteristics of nonlinear and dynamic characteristics of slide level traffic characteristics. Assuming that the compressibility of the liquid can be ignored in the valve, and the valve has an ideal response capability, that is, the opening of the spool and the valve pressure drop corresponding to the changes in the flow can occur instantaneously ${ }^{[11]}$.

Fig.2 is principle diagram of valve controlled cylinder. In order to study the nonlinear characteristics of the valve port and valve flow nonlinear ${ }^{[12]}$, suppose that the dead zones of throttle window 1 and 2 are $\Delta$, the dead zones of throttle window 3 and 4 are respectively $\Delta_{1}$ and $\Delta_{2}$. Flow into and out the cylinder are respectively $\mathrm{Q}_{1}$ and $\mathrm{Q}_{2}$.

The four valve ports are regarded as variable nonlinear liquid resistance, and its damping by the spool displacement caused by the opening amount of $X$ regulation, when the valve port pressure drop is $P$, the flow equation through the valve port is ${ }^{[13]}$ :

$$
Q=K x \sqrt{P}
$$

Where: $K$ - Comprehensive coefficient of valve port, it expresses wetted perimeter and flow coefficient.

We assume that comprehensive coefficient of four valve ports are respectively $K_{21}, K_{14}, K_{23}, K_{34}$, then flow equation of four valve ports can be derived: 


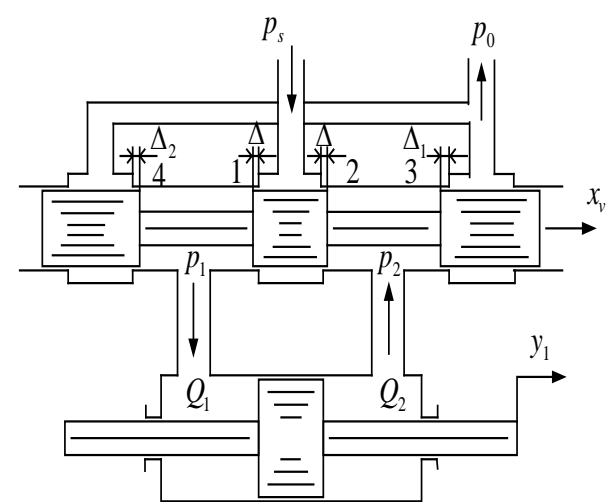

Figure 2. Principle diagram of valve controlled cylinde

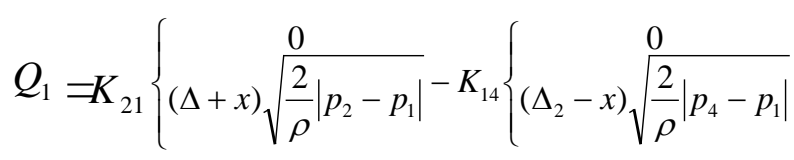

other

$$
\begin{gathered}
(\Delta+x)>0,\left(\Delta_{2}-x\right)>0 \\
Q_{\bar{z}-} \quad K_{21}\left\{(\Delta+x) \sqrt{\frac{0}{\frac{2}{\rho}\left|p_{2}-p_{1}\right|}}-K_{23}\left\{\left(\Delta_{1}-x\right) \sqrt{\frac{2}{\rho}\left|p_{3}-p_{2}\right|}\right.\right.
\end{gathered}
$$

other

$$
\begin{aligned}
& (\Delta+x)>0,\left(\Delta_{1}-x\right)>0
\end{aligned}
$$

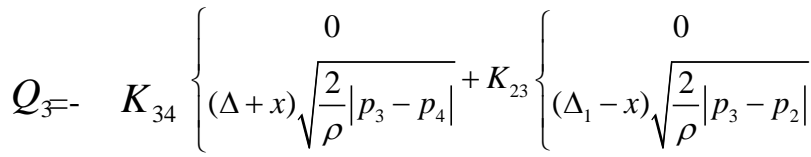

other

$$
\begin{aligned}
& (\Delta+x)>0,\left(\Delta_{1}-x\right)>0 \\
& Q_{4}=-K_{34}\left\{(\Delta+x) \sqrt{\frac{2}{\rho}\left|p_{3}-p_{4}\right|}+K_{14}\left\{\left(\Delta_{2}-x\right) \sqrt{\frac{2}{\rho}\left|p_{4}-p_{1}\right|}\right.\right.
\end{aligned}
$$

other

$$
(\Delta+x)>0,\left(\Delta_{2}-x\right)>0
$$

Where: $\rho$ - Fluid density $\left(\mathrm{kg} / \mathrm{m}^{3}\right) ; \mathrm{p}_{1}, \mathrm{p}_{2}, \mathrm{p}_{3}, \mathrm{p}_{4}$-Pressure drop at each valve port $\left(\mathrm{N} / \mathrm{m}^{2}\right)$.

The relationship between the opening of the servo valve spool and the input current can be expressed as: (6)

$$
x=\frac{K_{s v}}{\left(\frac{s}{\omega_{s v}}\right)^{2}+2 \frac{\xi_{s v}}{\omega_{s v}} s+1} i
$$

Where: $\mathrm{K}_{\mathrm{sv}}$ - Servo valve coefficient (m/A); $\omega_{s v}$ - The bandwidth of the servo valve (rad/s); $\xi_{s v}$-Damping ratio of servo valve, dimensionless; i - Servo valve input current (A).

Define the hydraulic resistance of the servo valve as:

$$
R_{v}=\frac{\sqrt{2 \rho}}{2 C_{d} w}
$$

According to the programming principles of 20-SIM simulation software, Set four resistive elements R1 to R4, the flow characteristics of four throttle windows are described respectively ${ }^{[14]}$ :

$$
\text { R1: }\left\{\begin{array}{c}
p . f=0 \\
p . f=\operatorname{sqrt}(\operatorname{abs}(p . e)) \times \operatorname{sign}(p . e) /\left(R_{v} \times(x-\Delta)\right) \\
x \leq \Delta \\
x>\Delta
\end{array}\right.
$$

(7)

$$
\text { R2: }\left\{\begin{array}{r}
p \cdot f=0 \\
p . f=\operatorname{sqrt}(\operatorname{abs}(p . e)) \times \operatorname{sign}(p . e) \\
-x \leq \Delta \\
-x>\Delta
\end{array}\right.
$$$$
p . f=\operatorname{sqrt}(\operatorname{abs}(p . e)) \times \operatorname{sign}(p . e) /\left(R_{v} \times(x+\Delta)\right)
$$

$$
\begin{gathered}
\text { R3: }\left\{\begin{array}{c}
p . f=0 \\
p . f=\operatorname{sqrt}(\operatorname{abs}(p . e)) \\
\times \operatorname{sign}(p . e) /\left(R_{v} \times\left(x-\Delta_{1}\right)\right. \\
x \leq \Delta_{1} \\
x>\Delta_{1}
\end{array}\right.
\end{gathered}
$$




$$
\begin{aligned}
& -x \leq \Delta_{2} \\
& -x>\Delta_{2}
\end{aligned}
$$

Fig.3 is bond graph model for a electro hydraulic servo valve, Se representation of constant potential source for hydraulic system, constant potential source Sy for oil return; Saturation characteristics of servo valve is described as saturation function; The friction characteristics of the valve are considered, Using resistive element module R0 representation; $\mathrm{Ky}$ and $\mathrm{Kz}$ are used to select throttling window1, 3, 2 and 4, there equations are:

Ky: $\quad$ output $=0.5 \times(\operatorname{abs}($ input $)+$ input $)$

Kz: $\quad$ output $=0.5 \times($ input-abs(input $))$

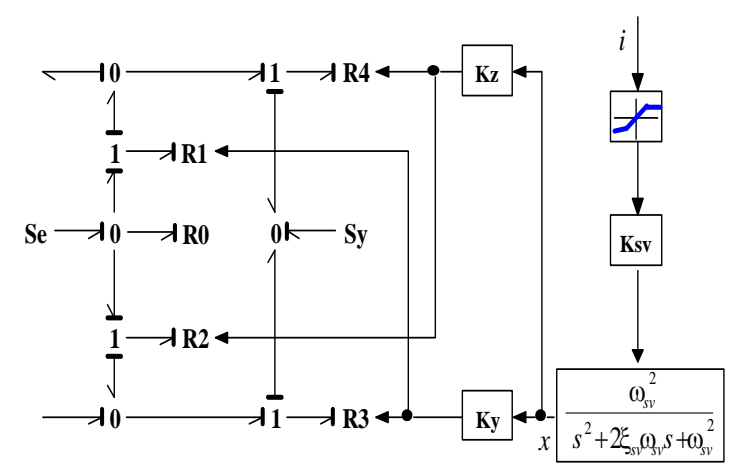

Figure 3. Bond graph model for a electro hydraulic servo valve

\section{Bond Graph Model of Hydraulic Cylinder}

For the hydraulic cylinder, the oil outlet is connected to the cavity pressure and external force as the input, output is flow and piston rod movement and velocity value, and the differential equations describing the hydraulic cylinder motion can be expressed as ${ }^{[15]}$.

$$
\left\{\begin{array}{l}
\dot{x_{1}}=x_{2} \\
\dot{x_{2}}=\frac{1}{M}\left(A\left(p_{1}-p_{2}\right)-B x_{2}-F_{L}\right) \\
Q=A x_{2}
\end{array}\right.
$$

Where: M - Piston quality of hydraulic cylinder(kg); B Friction coefficient of hydraulic cylinder piston and cylinder(Ns/m); A - Effective area of hydraulic cylinder piston $\left(\mathrm{m}^{2}\right) ; \mathrm{p}_{1}, \mathrm{p}_{2}$ - Hydraulic cylinder two chamber pressure value $\left(\mathrm{N} / \mathrm{m}^{2}\right) ; \mathrm{x}_{1}$ - Piston rod displacement(m); $\mathrm{x}_{2}$-Piston rod speed $(\mathrm{m} / \mathrm{s}) ; \mathrm{Q}$-Piston rod movement required flow $\left(\mathrm{m}^{3} / \mathrm{s}\right)$.

According to the rules of bond graph, the liquid capacity of the two cavity of the hydraulic cylinder is obtained:

$$
\begin{aligned}
& C_{1}=\frac{A\left(L+x_{1}\right)}{\beta_{e}} \\
& C_{2}=\frac{A\left(L-x_{1}\right)}{\beta_{e}}
\end{aligned}
$$

Where: L - Stroke of hydraulic cylinder (m); $\beta_{\mathrm{e}}$ - Bulk modulus of hydraulic oil $\left(\mathrm{N} / \mathrm{m}^{2}\right)$.

Fig.4 is bond graph model for a cylinder, the resistive element $\mathrm{Rg}$ is used to describe the internal leakage of the hydraulic cylinder, the resistive element $\mathrm{Bc}$ is used to describe the Coulomb friction and Viscous friction acting on the piston rod of the hydraulic cylinder. Inertial element M describes the quality of hydraulic cylinder piston and piston rod assembly. Capacitive elements C1 and C2 are used to describe the volumetric effect of the two chamber of the hydraulic cylinder, as shown in formula (19) and (20), the displacement of the piston rod of the hydraulic cylinder is obtained through an integral link, and the input to the capacitive element C1 and C2 is used to describe the time varying characteristics of the displacement of the cylinder with the piston rod.

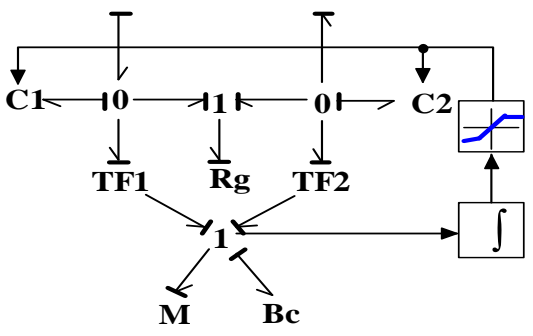

Figure 4. Bond graph model for a cylinder

\section{Bond Graph Model of Electro Hydraulic FORCE SERVO SYSTEM}

According to the basic principle of bond graph modeling, if the sub module in the form of a electro hydraulic servo valve, coupled with the signal source, controller module, and the signal processing part, on the establishment of electric hydraulic force servo system bond graph model as shown in Fig. 5. The diagram with capacitive element Ke describe the force sensor flexibility, capacitive element $\mathrm{K}$ describe the flexibility of spring. The inertial element M1 is used to represent the inertial load, and the resistive element, R, represents the frictional force acting on the inertial load. 


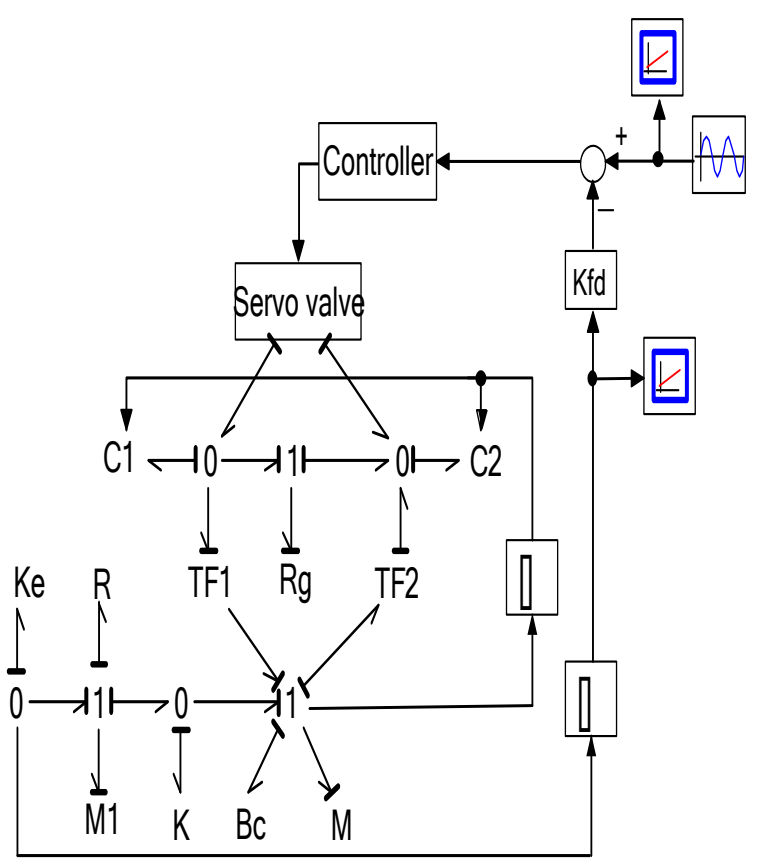

Figure 5. Bond graph model for the electro hydraulic force servo system

\section{Simulation Research of Electro Hydraulic FORCE SERVO SYSTEM}

According to bond graph model of electric hydraulic force servo system, the simulation is made by substituting actual parameters, the analysis of the overall characteristics of the system, and considering the system key valve friction, hydraulic cylinder piston friction, hydraulic cylinder cavity time varying and nonlinear characteristics of valve flow is made to research correctness of the graph model. This provides a foundation for further analysis of parameters effect on the system and the main factors influencing the precision of the system, but also provides the basis for further improving the accuracy and performance of electric hydraulic force servo system, the design of new and more efficient controller.

Fig. 6 is the output simulation curve of the system under different frequency signal input, the frequency of the input signal is $1 \mathrm{~Hz}, 5 \mathrm{~Hz}, 10 \mathrm{~Hz}$ and $20 \mathrm{~Hz}$, and curve 1 is the input curve, curve 2 is the output curve. It can be seen from the figure, at low frequency, the output of the system can track the input signal, and the reproducibility is very good, when the frequency is higher, the amplitude of the output signal of the system decreases, and there are obvious lag phase. We can know from the simulation curve, when the input signal is $20 \mathrm{~Hz}$, the output signal amplitude attenuation is about $80 \%$ of the input value, and the phase lag is serious. The correctness of the model is verified, the problems of high frequency are found, and these problems need to be further improved.
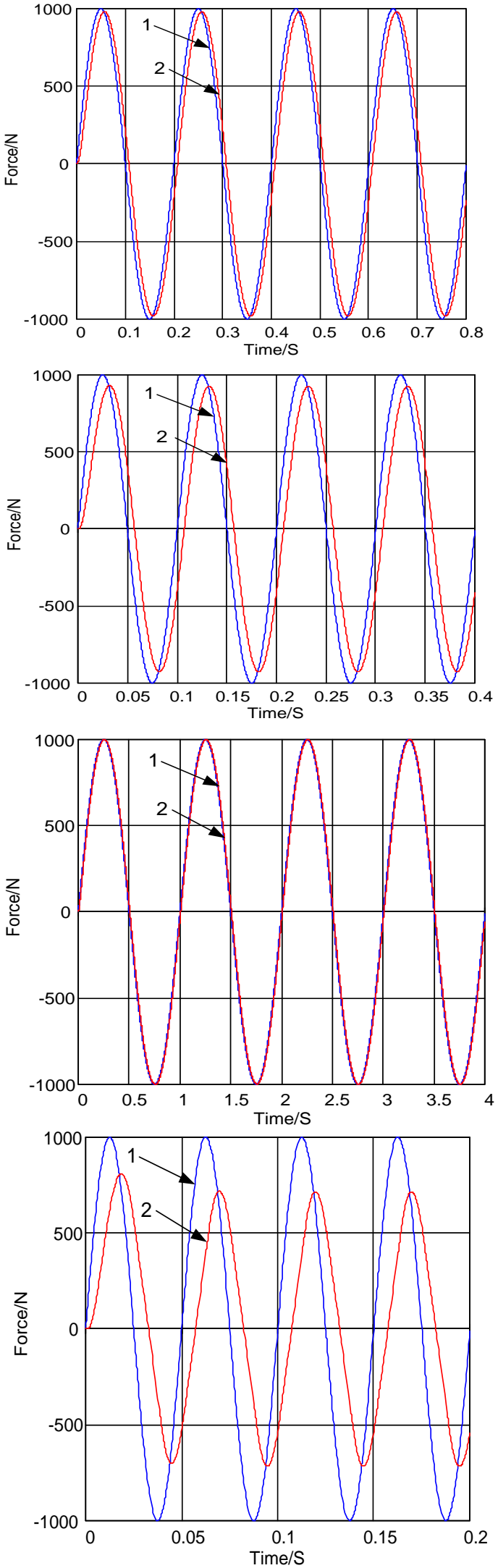

Figure 6. Simulation curve of electro hydraulic force servo system 


\section{CONCLUSION}

Aiming at electric hydraulic force servo system time varying nonlinear characteristics, nonlinear friction of different position in the system, valve orifice flow nonlinear etc. difficult to model characteristics, this paper use the advantage of bond graph theory containing variety of nonlinear, suitable for simulating the nonlinear system to establish electric hydraulic force servo system bond graph model. During in this period, the bond graph model of electro hydraulic servo valve is established, including electrical, magnetic and mechanical motion equation model,and the modeling process of nonlinear characteristics of valve port flow is considered; At the same time, the bond graph model of hydraulic cylinder is established according to the differential equations of hydraulic cylinder motion, and time varying characteristics of the hydraulic cylinder cavity with the piston rod displacement is considered. The simulation results verify the correctness of the system model, and has a certain reference value of practical application, also found in the high frequency motion amplitude and phase error between the model output and input is large, the need to continue to improve in the follow-up study.

\section{ACKNOWLEDGMENT}

This work is supported by National Natural Science Foundation of China (51405113).

\section{REFERENCES}

[1] Cong Zilong, Yuan Zhaohui, YANG Fang, Zhang Jingchong, HighOrder Integral Sliding Mode Control for Passive Electric Hydraulic Servo System, Machine Tool \& Hydraulics, Jul. 2014, Vol. 42, No. 13, 56-59;

[2] Tang Lingfeng, Wang Lei, Research on Pole Placement Optimization of Electro Hydraulic Servo System, Mechanical Drive, 2006,Vol. 30, No. 6, 25-28;
[3] Liu Shudao, Yang Xianping, Study of the Optimal Control Method Based on Electro hydraulic Force Servo System, Machine Tool \& Hydraulics, 2003, No. 5, 78-79;

[4] J. Thoma, Bond Graphs and Practical Simulation, Simulation Practice and Theory, 1999 (7), 401-417;

[5] Ren Jintang, Bond graph theory and its application, Shanghai Jiao Tong University press, 1992, Shang Hai, 9-15;

[6] Zhang Shangcai, Bond graph simulation of engineering system, Machinery Industry Press, 1993, Bei Jing, 121-130;

[7] Quan Lingxiao, Sheng Shiwei, Chen Gang, Dynamic Performance Test of Electro-hydraulic Servo Valve Based on Joint Test and Control, Transactions of the Chinese Society for Agricultural Machinery, Vol.47, No.1, 2016, 377-382;

[8] Shujiro Dohta, Tetsuya Akagi, Yusuke Masago, et al., Development of Small-sized Digital Servo Valve for Wearable Pneumatic Actuator, Procedia Engineering, Vol. 41, 2012, 97-104;

[9] Xu Yimin, Analysis of the CAT Data Progress Error for Electro Hydraulic Servo Valve Dynamic Phase Frequency Characteristic, Chinese Journal of Mechanical Engineering, Vol.41, No. 1, 2005, 4649;

[10] Wang Shoukun, Wang Junzheng, Li Jincang, A New Testing Method for Dynamic Performance of Servo Valves Based on Displacement Measurement. Journal of Beijing Institute of Technology, 2011,Vol.31, No. 6, 666- 669;

[11] Wang Qiang, Wu Zhangyong, Li Hongxing, Wu Pengfei, Liu Jianqiang,Simulation Analysis of Electro Hydraulic Servo Velocity Control System Based on AMESim, The Fifth National Conference on Fluid Power Transmission and Control and the 2008 Conference on Hydraulics and Pneumatics of China Aviation Society, 2008, Bei Jing;

[12] Yi Menglin, Zhu Fan, Zhou Zhanjiang, Servo Valve in Electro Hydraulic Loading System, Hydraulic and Pneumatic. No.1, 1997, 22-25;

[13] Tian Yuandao, Numerical Simulation and CAD Design Program of Double Nozzle Flapper Force Feedback Electro Hydraulic Servo Valve, Machine Tool \& Hydraulics, No. 6, 1986, 16-21;

[14] Xiong Wei, Bao Gang, Li Hongren, Introduction and Application of 20-Sim Software, Hydraulic and pneumatic, No.4, 2000, 31-33;

[15] Andrew Alleyne, Rui Liu, A Simplified Approach to Force Control for Electro Hydraulic Systems, Control Engineering Practice, No.8. $2000,1347-1356$. 